\title{
Longitudinal Evaluation of Compressor/Nebulizer Performance
}

\author{
Samah Awad MBBS, David K Williams MPH PhD, and Ariel Berlinski MD
}

\begin{abstract}
BACKGROUND: Inhaled medications are the mainstay of treatment for maintenance of lung health in patients with cystic fibrosis (CF). Compressor/nebulizer units are used an average of 100-120 $\mathrm{min} / \mathrm{d}$ by patients with CF. Each compressor/nebulizer has unique flow/pressure characteristics that affect particle size distribution and drug output rate. Few data are available regarding longitudinal performance of compressor/nebulizers. We hypothesized that their use over a 24-wk period under conditions similar to those of patients with $\mathrm{CF}$ would affect their performance. METHODS: Four new units of compressor/reusable nebulizers from 3 brands (Pari Vios/Pari LC Plus, Pulmo-Aide 5650D/Viox, and Inspiration Elite/SideStream Plus) commonly used by patients with CF were tested. Compressor/nebulizers were operated for $1 \mathrm{~h}$ twice daily $5 \mathrm{~d} / \mathrm{wk}$ for $24 \mathrm{wk}$. Compressor flow/pressure characteristics were measured every $6 \mathrm{wk}$. Maximal flow was recorded without and with the nebulizer (MF and MF/NEB, respectively). Pressure was recorded at zero flow (MP) and at MF/NEB (P/NEB). Particle size distribution, inhaled mass (IM), and IM in respirable range were evaluated at baseline and every 12 wk. RESULTS: Vios had statistically significant declines in MP and P/NEB at each measurement compared with baseline (45.8 and 32.6 psi for MP and 16.7 and 14.3 psi for $\mathrm{P} / \mathrm{NEB}$ at wk 0 and 24, respectively, $P<.05$ ), but other compressors did not. MF and MF/NEB were stable over time but significantly varied among brands. Vios had the greatest slope of flow/pressure relationship (Vios > Pulmo-Aide > Inspiration Elite). Two Vios units stopped working at wk 11 and 24, respectively. All compressors maintained baseline IM, IM in respirable range, and aerosol characteristics. CONCLUSIONS: Long-term use of compressor/ nebulizers in a regimen similar to that of patients with $\mathrm{CF}$ affected their performance. Pari Vios was the most affected brand, with declines in MP and P/NEB and 2 units that stopped working. Measurement of MF and MF/NEB could help identify compressors that are likely to fail. Key words: Compressor; nebulizer; flow; pressure; aerosol; particle size; breathing simulation; cystic fibrosis. [Respir Care 2014;59(7):1053-1061. () 2014 Daedalus Enterprises]
\end{abstract}

\section{Introduction}

Cystic fibrosis (CF) is a fatal autosomal recessive disease affecting multiple organs. ${ }^{1}$

\footnotetext{
At the time of this study, Dr Awad was affiliated with the Pulmonology Section, Department of Pediatrics, College of Medicine, University of Arkansas for Medical Sciences, Little Rock, Arkansas. She is presently affiliated with the Department of Pediatrics. College of Medicine, Jordan University of Science and Technology, Irbid, Jordan. Dr Williams is affiliated with the Department of Biostatistics, College of Public Health, University of Arkansas for Medical Sciences, and Dr Berlinski is affiliated with the Pediatric Aerosol Research Laboratory, Arkansas Children's Hospital Research Institute and the Pulmonology Section, Department of Pediatrics, College of Medicine, University of Arkansas for Medical Sciences, Little Rock, Arkansas.
}

Dr Awad presented a version of this paper in abstract format at the
The majority of mortality and morbidity is related to lung disease. ${ }^{2}$ The $\mathrm{CF}$ gene defect impairs cystic fibrosis transmembrane regulator protein function leading to airway-surface-liquid depletion, loss of mucociliary clearance, and a vicious circle of inflammation and chronic bacterial infections. ${ }^{3}$ An aggressive approach to treat $\mathrm{CF}$ lung disease has improved pulmonary outcomes and extended median predicted age of survival in the last 3 de-

\footnotetext{
American Thoracic Society International Meeting, held May 17-22, 2013, in Philadelphia, Pennsylvania.

This research was supported in part by the University of Arkansas for Medical Sciences College of Medicine Children's University Medical Group Fund grant program. The Pediatric Aerosol Research Laboratory at Arkansas Children's Hospital Research Institute was partially established by and receives partial support from the George Endowment for
}

DOI: 
cades from 18 y of age in 1980 to 38.3 in $2010 .^{2}$ Inhaled medications constitute the main treatment options recommended for chronic maintenance of lung health in patients with CF. Recent guidelines have provided recommendations for the use of the following inhaled medications: tobramycin, dornase alfa, hypertonic saline, and $\beta_{2}$-adrenergic receptor agonists. ${ }^{4,5}$

The United States Cystic Fibrosis Foundation recommends the use of inhaled tobramycin in patients older than $6 \mathrm{y}$ with mild, moderate, and severe lung disease who are chronically colonized by Pseudomonas aeruginosa. Tobramycin is administered at a dose of $300 \mathrm{mg}$ twice daily on alternating months ( $28 \mathrm{~d}$ on/28 d off), and it has been shown to increase lung function and decrease pulmonary exacerbations. ${ }^{4,5}$ Tobramycin solution for inhalation is registered under the brand name Tobi (Novartis Pharmaceuticals Corporation, East Hanover, New Jersey) (300 mg/5 mL) and is used in combination with a Pari LC Plus reusable jet nebulizer (Pari Respiratory Equipment, Midlothian, Virginia) and a suitable compressor, which has a flow of $4-6 \mathrm{~L} / \mathrm{min}$. ${ }^{6}$ It is also available outside the United States as Bramitob (300 mg/4 mL) and used in combination with either Pari LC Plus reusable jet nebulizer and the Pari Turbo Boy compressor or Pari LC Sprint and Pari Boy Sx compressor. ${ }^{7}$ Twice daily inhalation of tobramycin can take $40 \mathrm{~min} / \mathrm{d}$.

The Cystic Fibrosis Foundation also recommends the use of recombinant human dornase alfa for patients older than $6 \mathrm{y}$ with a variable spectrum of $\mathrm{CF}$ lung disease. Dornase alfa (Pulmozyme) reduces viscoelasticity of CF sputum by hydrolyzing extracellular DNA released by neutrophils in the inflamed airways and therefore enhancing mucociliary clearance. ${ }^{8}$ It is available in ampoules of $2.5 \mathrm{mg} / 2.5 \mathrm{~mL}$, given once daily and used in jet nebulizers connected to a compressor. In clinical trials, device combinations such as Durable SideStream with Mobilaire, Durable SideStream with Porta-Neb, Hudson T Up-draft II with Pulmo-Aide, Respirgard II Nebulizer with PulmoAide, Pari LC Plus with Pari Proneb, and Pari Baby with

Asthma. Dr Berlinski served as principal investigator in clinical trials sponsored by Johnson \& Johnson, MPEX Pharmaceutical, Gilead, Philips, Genentech, Vertex Abvie, Janssen, and Aptalis and was recipient of an unrestricted educational grant from S\&T Technologies. The other authors have disclosed no conflicts of interest.

Correspondence: Ariel Berlinski MD, Department of Pediatrics, Pulmonary Medicine, University of Arkansas for Medical Sciences, 1 Children's Way, Slot 512-17, Little Rock, Arkansas 72202. E-mail: BerlinskiAriel@uams.edu.

Supplementary material related to this paper is available at http:// www.rcjournal.com.

DOI: $10.4187 /$ respcare. 02776

\section{QUICK LOOK}

\section{Current knowledge}

Inhaled medications are often delivered at home for maintenance of lung health in patients with chronic respiratory disease. In combination with a jet nebulizer, compressors are used an average of $2 \mathrm{~h} / \mathrm{d}$. Each compressor/nebulizer has unique flow/pressure characteristics that affect medication delivery.

\section{What this paper contributes to our knowledge}

The long-term use of compressor/nebulizer units under simulated clinical conditions affects device performance. Pari Vios experienced significant changes in flow/pressure characteristics, including 2 units that failed. Periodic assessment of maximum flow may identify compressors prone to failure.

Pari Proneb have been used. The estimated nebulization time ranges between 6 and 8 min.9,10

The Cystic Fibrosis Foundation also recommends the chronic use of nebulized hypertonic saline in patients with $\mathrm{CF}, 6 \mathrm{y}$ of age and older, to improve lung function. ${ }^{4,5} \mathrm{By}$ acting as an osmolar agent, hypertonic saline helps by hydrating the periciliary layer of the respiratory epithelium, hence enhancing airway clearance. ${ }^{11}$ Administration of $4 \mathrm{~mL}$ of $7 \%$ saline twice daily improved $\mathrm{FEV}_{1}$, respiratory symptoms, and mucus clearance; inhalation time can take $15 \mathrm{~min} / \mathrm{d}$. For patients with $\mathrm{CF}, 6 \mathrm{y}$ of age and older, the Cystic Fibrosis Foundation also recommends the chronic use of inhaled $\beta_{2^{-}}$ adrenergic receptor agonists to improve lung function. ${ }^{4,5} \mathrm{Neb}-$ ulization time can reach $30 \mathrm{~min}$.

Patients with CF use their nebulizers an average of 100 $120 \mathrm{~min} / \mathrm{d}$. Such use may reduce the performance of the compressors used to run these nebulizers. Manufacturers typically provide a 5-y warranty on the compressors, but they do not specify in their operations manuals the number of hours that they will run. Many third-party payers only allow compressor renewal every $5 \mathrm{y}$. Our clinical experience at the Arkansas Children's Hospital Cystic Fibrosis Care Center as well as frequent reports in CF-related professional Listservs indicate that the life span of compressors used by patients with $\mathrm{CF}$ is shorter than claimed by manufactures and covered by third-party payers.

Although several types of nebulizers are available, jet nebulizers are the most popular due to their low cost and widespread availability. Compressed air is needed for jet nebulizers to aerosolize liquid solutions or suspension and convert them into mist. ${ }^{12,13}$ Compressors constitute the only available air flow source at home and can be also used in hospital settings. The compressor gas flow/pressure relationship and patient-related factors affect the neb- 


\section{Longitudinal Evaluation of Compressor/Nebulizer Performance}

ulizer performance in terms of droplet size distribution and drug output rate. ${ }^{14,15}$ Lower gas flows lead to longer nebulization time and larger particle size aerosols. ${ }^{15}$ The former hinders adherence to therapies, and the latter could alter the site of intrapulmonary deposition. Therefore, information about performance of compressor/nebulizer systems is important for patient care.

Although several authors have reported the characteristics of different compressors and nebulizers, little is known about the effect of long-term use on their performance. ${ }^{16-20}$ Standaert et $\mathrm{al}^{21}$ determined particle size distribution and output rate of the Pari LC durable nebulizer after 100 runs and reported that particle size remained stable.

In this study, we evaluated the performance of 3 pairs of compressor/nebulizer combinations over a 24-wk period of use typical of a patient with CF. We hypothesized that such use of compressor/nebulizer units will affect their flow/pressure, drug output, and aerosol characteristics. These changes are expected due to progressive deterioration of the compressor/nebulizer units and could have relevant implications for lung deposition and medication efficacy of aerosol treatments. In addition, we hypothesized the presence of differences in performance among different compressor/nebulizer systems.

\section{Methods}

\section{Compressors and Nebulizers}

Four new compressor units from 3 different brands were used in our study with the reusable nebulizer recommended by the manufacturers: Pari Vios compressor with Pari LC Plus reusable nebulizer (Pari Respiratory Equipment), Pulmo-Aide model 5650D compressor with Viox 1 reusable nebulizer (DeVilbiss Healthcare, Somerset, Pennsylvania), and Inspiration Elite model HS456 compressor with SideStream Plus model HS870 durable nebulizer (Philips Respironics, Parsippany, New Jersey). The Viox nebulizer is a constant output nebulizer, whereas Pari LC Plus and SideStream Plus are breath-enhanced nebulizers. The Inspiration Elite compressor has a self-resetting pressure relief valve that opens at $33 \mathrm{psi}$. The technical specifications provided by the manufacturers can be seen in Table 1 . These devices were chosen because they are the most commonly used and their manufacturers advertise their use for treatment of cystic fibrosis.

\section{Study Design}

Each compressor/nebulizer was operated without a solution for $1 \mathrm{~h}$ twice daily, $5 \mathrm{~d} / \mathrm{wk}$ for $24 \mathrm{wk}$. The corresponding nebulizer was connected to each compressor. The same combinations of compressor/nebulizer units were used through the study. Environmental temperature and
Table 1. Compressor Specifications Provided by Manufacturers

\begin{tabular}{lccccr}
\hline \hline Compressor & $\begin{array}{c}\text { Weight } \\
(\mathrm{lb})\end{array}$ & $\begin{array}{c}\text { Dimensions, } \\
\text { Length } \times \text { Width } \\
\times \text { Height (in })\end{array}$ & $\begin{array}{c}\text { MF } \\
(\mathrm{L} / \mathrm{min})\end{array}$ & $\begin{array}{c}\text { MF/NEB } \\
(\mathrm{L} / \mathrm{min})\end{array}$ & $\begin{array}{c}\text { MP } \\
(\mathrm{psi})\end{array}$ \\
\hline Pari Vios & 3 & $6.5 \times 6.5 \times 3.75$ & 8.5 & 4.5 & 34 \\
Pulmo-Aide & 7.1 & $10.1 \times 10.5 \times 6.5$ & $\geq 9$ & $\mathrm{NA}$ & $\geq 30$ \\
Inspiration Elite & 3.3 & $7.5 \times 7.5 \times 4.2$ & 8.2 & $\mathrm{NA}$ & 33
\end{tabular}

MF = maximal flow

$\mathrm{MF} / \mathrm{NEB}=$ maximal flow with the nebulizer connected to the compressor

$\mathrm{MP}=$ maximal pressure

$\mathrm{NA}=$ information not provided by the manufacturer in the compressor manual

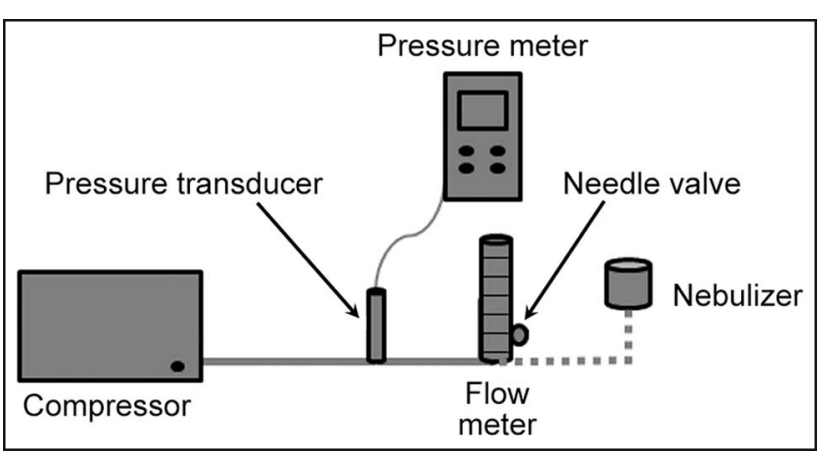

Fig. 1. Experimental setup used to measure compressor flow/ pressure characteristics.

humidity were recorded at time of operation $\left(23^{\circ} \mathrm{C} \pm 1.4^{\circ} \mathrm{C}\right.$ and $42.6 \% \pm 5.7 \%$, respectively). Measurements of flows and pressures were done at wk 0,6,12,18, and 24. Breathing simulation testing and particle size distribution measurements were done at wk 0,12 , and 24 . Compressor filters were periodically reviewed for presence of dirt. The study was performed at the Pediatric Aerosol Research Laboratory, Arkansas Children's Hospital Research Institute, Little Rock, Arkansas.

\section{Flow and Pressure Measurements}

Previously published methodologies were used to measure flow and pressure characteristics of compressor/nebulizer systems (Fig. 1). ${ }^{16,17,19}$ The outlet of each compressor was connected in line with tubing to a pressure meter with a transducer with a maximum of $72.5 \mathrm{psi}$ and resolution of $0.1 \mathrm{psi}$ (model 840065, Sper Scientific, Scottsdale, Arizona) and thence to a flow meter with a range of 2-20 L/min (Cole-Parmer Instruments, Vernon Hills, Illinois). The flow meter had a needle valve that allowed flow adjustment. Maximal flow (MF) was recorded as the flow ( $\mathrm{L} / \mathrm{min}$ ) each compressor developed when the needle valve was completely open. Flow decrements of $1 \mathrm{~L} / \mathrm{min}$ were used between flows similar to MF and the maximal flow with the nebulizer connected to the compressor (MF/NEB). Flow decrements of $0.5 \mathrm{~L} / \mathrm{min}$ were used from between 


\section{Longitudinal Evaluation of Compressor/Nebulizer Performance}

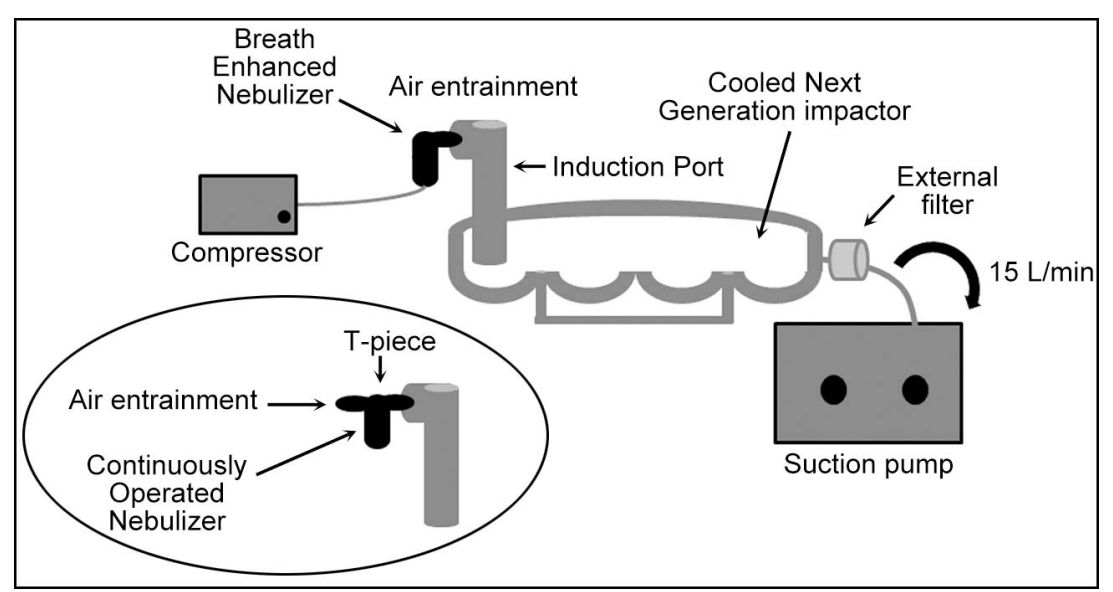

Fig. 2. Experimental setup used to measure particle size of aerosols generated by compressor/nebulizer systems.

flows similar to $\mathrm{MF} / \mathrm{NEB}$ to $2 \mathrm{~L} / \mathrm{min}$, and then flow was decreased from $2 \mathrm{~L} / \mathrm{min}$ to $0 \mathrm{~L} / \mathrm{min}$. These resulted in 12 , 17, and 17 data points for Vios, Pulmo-Aide, and Inspiration Elite, respectively. Flow was adjusted with the needle valve, and pressure was measured at each flow. The pressure that the compressor developed at zero flow (needle valve completely closed) was recorded as the maximal pressure (MP). Measurements were done after 2 min of operation. The nebulizer without a solution was then connected to the flow meter, and MF/NEB and the pressure measured at MF/NEB (P/NEB) were recorded.

\section{Particle Size Analysis}

Particle size distribution was measured by cascade impaction. A Next Generation Impactor (NGI, MSP Corporation, Shoreview, Minnesota) calibrated at $15 \mathrm{~L} / \mathrm{min}$ was cooled to $4^{\circ} \mathrm{C}$ for $90 \mathrm{~min}$ and used within $5 \mathrm{~min}$ of removal from the refrigerator. ${ }^{22}$ Albuterol sulfate $(2.5 \mathrm{mg} / 3 \mathrm{~mL}$, Nephron Pharmaceuticals, Orlando, Florida) was loaded in the nebulizer. The nebulizer was connected to the inlet of the induction port of the NGI and was operated for 4 min (Fig. 2). Air entrainment was allowed through the T-piece in the Viox nebulizer and through the inspiratory valve in the Pari LC Plus and SideStream Plus nebulizers. Upon completion, all the collection cups, internal and external filters, and nebulizer cup were diluted with ultrapure water and tested for albuterol concentration via spectrophotometry at $276 \mathrm{~nm}$ (BioMate $3 \mathrm{UV}$ visible spectrophotometer, Thermo Electron Corporation, Waltham, Massachusetts). ${ }^{22}$ The following parameters were calculated using CITDAS 3.1 software (Copley Scientific, Nottingham, United Kingdom) according to United States Pharmacopeia and European Pharmacopeia recommendations: mass median aerodynamic diameter (MMAD), geometric SD (GSD), and percentage of drug mass contained in particles $<5 \mu \mathrm{m}(\mathrm{P} \%<5) .{ }^{22}$ Nebulizers were disassembled, cleaned with ultrapure water, and air-dried.

\section{Breathing Simulation}

This methodology is used to study aerosol output of nebulizers and allows an accurate evaluation of devices that have an increase in their aerosol output during inspiration, such as breath-enhanced nebulizers. ${ }^{23}$ A breathing simulator is a computerized piston pump that allows programming of respiratory parameters to mimic different breathing conditions. Calibration of breathing simulator (Pari Compass) was verified at the beginning of each testing by a mass flow meter (model 4043, TSI, Shoreview, Minnesota) and its associated software. ${ }^{24}$ Nebulizer dry weight was obtained while still empty using a precision scale. Albuterol sulfate $(2.5 \mathrm{mg} / 3 \mathrm{~mL}$, Nephron Pharmaceuticals Corporation) was loaded in the nebulizer, and a new weight was obtained. The nebulizer was connected to the breathing simulator. A low dead space filter was interposed between them (inspiratory filter). A filter holder (Pari Respiratory Equipment) with a one-way valve was connected to the nebulizer to capture the exhaled aerosol (expiratory filter) to minimize operator exposure (Fig. 3). ${ }^{25}$ New filters (Pari Respiratory Equipment) were placed at the beginning of each experiment. The nebulizer was connected to the compressor and operated for $10 \mathrm{~min}$ and then reweighed to obtain the final weight. The following breathing pattern was used: tidal volume $500 \mathrm{~mL}$, breathing rate 12 breaths/min, inspiratory time $1.7 \mathrm{~s}$, and inspiratoryexpiratory ratio 1:2. After completion of nebulization, $5 \mathrm{~mL}$ of pure water were added to the nebulizer cup. The nebulizer was reweighed and then swirled, and the solution was tested for albuterol concentration. Albuterol remaining in the nebulizer cup was calculated as follows: ([final weight $+5 \mathrm{~mL}$ of pure water] - dry weight) $\times$ albuterol concentration. The inspiratory filter was placed in a $50-\mathrm{mL}$ tube with $10 \mathrm{~mL}$ of ultrapure water, and after vigorous shaking the solution was tested for albuterol concentration with spectrophotometry. The expiratory filter was dis- 


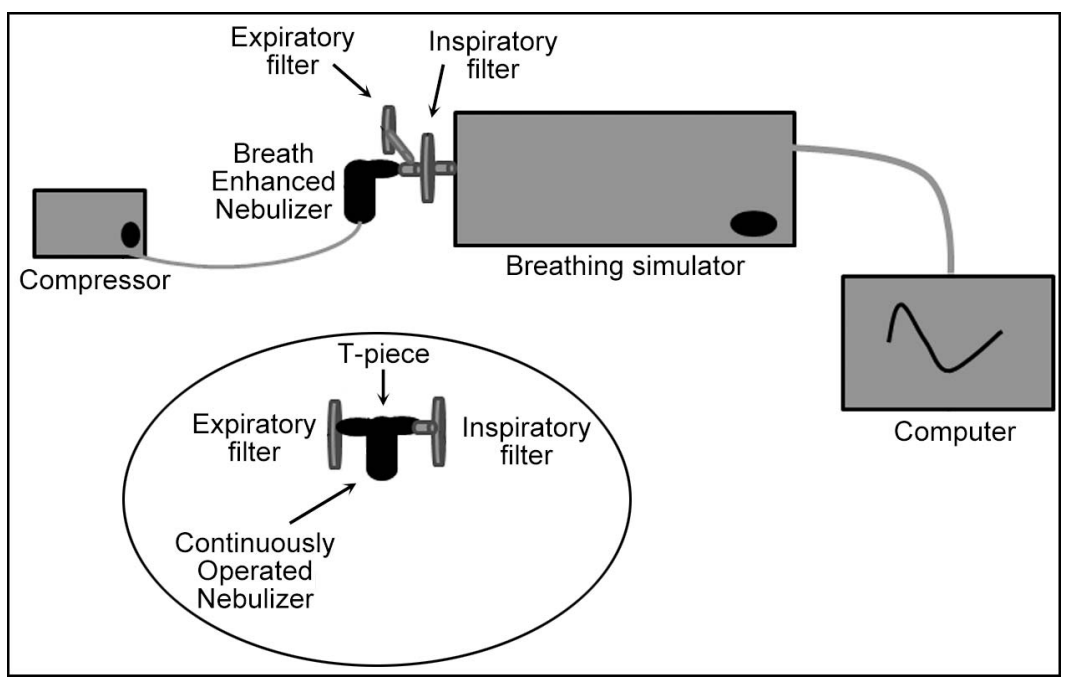

Fig. 3. Experimental setup used to measure drug output under simulated breathing conditions of different compressor/nebulizer systems.

carded. Nebulizers were disassembled, cleaned with ultrapure water, and air-dried. Inhaled mass (IM, $\mu \mathrm{g}$ ) was defined as the amount of the albuterol captured by the inspiratory filter. Inhaled mass in the respirable range (IM$\mathrm{RR})$ was calculated as $(\mathrm{IM} \times \mathrm{P} \%<5) / 100$.

\section{Statistical Analysis}

There were 5 parameters of interest related to pressure and flow measurements: MF, MP, MF/NEB, P/NEB, and slope of flow/pressure relationship without nebulizer (MF/MP slope). A nonlinear model of the form pressure $=\mathrm{a} \times$ exponential function $(\mathrm{b} \times$ flow $)$ was fit to the data, which provided the slope and maximal pressure estimates using the $5 \%$ level of significance. The Dunnet test was used to compare maximal pressure, flow, and flow/ pressure relationship slope at each time level to time zero. Analysis of variance followed by Tukey test was used to compare performance among the brands at wk $0,6,12,18$, and 24. Analysis of variance was used to compare particle size characteristics and breathing simulation results across devices. Analysis of variance for repeated measures was used to compare particle size characteristics and breathing simulation results at wk 0,12 , and 24 for each specific device. The Bonferroni method was used for post hoc analysis when multiple comparisons were required. A $P$ value $<.05$ was considered statistically significant. A statistical software package was used for data analysis (SAS 9.3, SAS Institute, Cary, North Carolina).

\section{Results}

The 4 tested units of Inspiration Elite and Pulmo-Aide compressors completed all planned studies. Two units of the Vios completed all planned studies. One unit stopped running after d 5 of wk 11 with a total run of $110 \mathrm{~h}$. Another unit completed all pressure/flow and simulation breathing studies, but, although the compressor was running, no aerosol was produced and no drug was recovered in the NGI at wk 24. This was verified in triplicate. Therefore, the $n$ for the Vios brand were 4 and 3 before and after wk 11, respectively, for all measurements except for NGI at wk 24, when $n$ was 2 .

\section{Flow and Pressure}

The flow/pressure relationship is depicted in Figure 4.

MF and MF/NEB. Pari Vios experienced a decline in $\mathrm{MF}$ at each time level compared with wk 0 without statistical significance (see Table 2 in text and Table 1 in the supplementary material available at http://www.rcjournal. com). However, the unit that stopped running at the end of wk 11 showed a decrease in MF from $9 \mathrm{~L} / \mathrm{min}$ at baseline to $7 \mathrm{~L} / \mathrm{min}$ at wk 6 . Additionally, the unit that malfunctioned in wk 24 showed a decrease in MF from $9 \mathrm{~L} / \mathrm{min}$ at baseline to $5 \mathrm{~L} / \mathrm{min}$ at wk 18 . Vios also had a decline in MF/NEB with time, which became statistically significant at wk $24(P=.045)$. The unit that malfunctioned in wk 24 had a decrease in MF/NEB from $4.5 \mathrm{~L} / \mathrm{min}$ to $4 \mathrm{~L} / \mathrm{min}$ and $3.5 \mathrm{~L} / \mathrm{min}$ at wk 12, 18, and 24 , respectively.

Pulmo-Aide and Inspiration Elite maintained baseline $\mathrm{MF}$ and $\mathrm{MF} / \mathrm{NEB}$ measurements throughout the 24-wk period. Pari Vios MF and MF/NEB were lower than PulmoAide and Inspiration Elite at all times $(P<.05)$. There was no difference in MF values between Pulmo-Aide and Inspiration Elite, but MF/NEB was higher in Pulmo-Aide than Inspiration Elite at all times $(P<.05)$. 


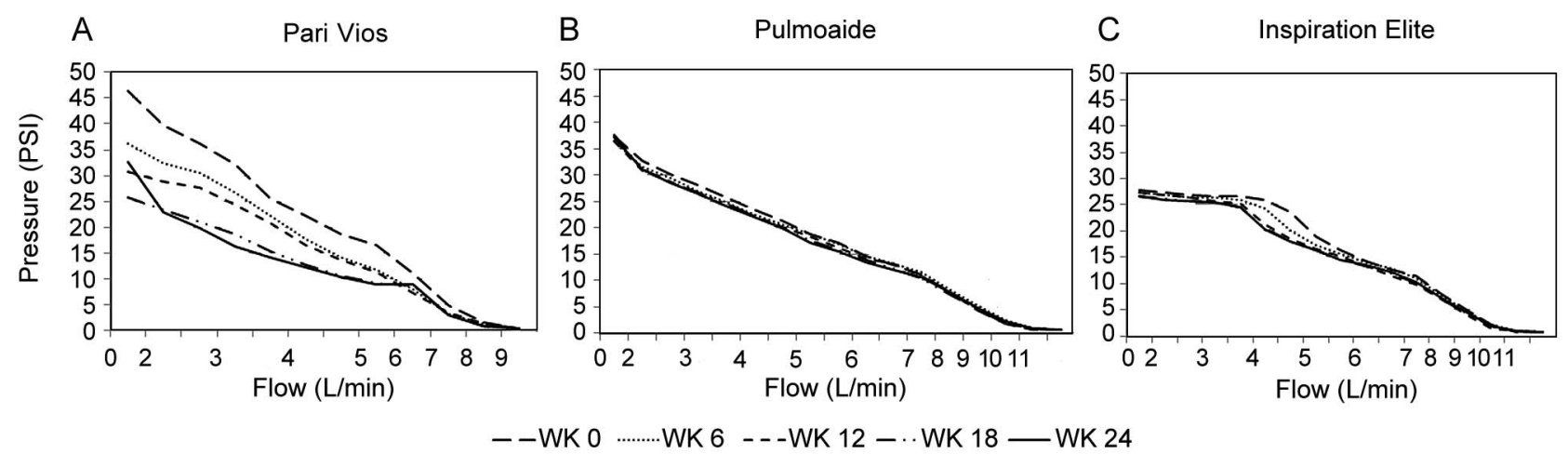

Fig. 4. Flow/pressure relationship of different compressors.

MP and P/NEB. Pari Vios had a significant decline $(P<.05)$ in MP at each time level compared with baseline, but the other brands did not. Additionally, it was noticed that MP showed erratic behavior, demonstrated by worsening during wk 18 with partial recovery during wk 24.

Vios and Pulmo-Aide demonstrated higher MP than Inspiration Elite. When performing all pairwise comparisons among the brands, Vios had greater MP than Inspiration Elite at all times except in wk 18. Pulmo-Aide was consistently greater than Inspiration Elite with significant differences at all times except at wk 6. Vios had greater MP than Pulmo-Aide at wk $0(P<.001), 6$, and 12. The trend is reversed at wk $18(P<.001)$ and wk 24, where PulmoAide had greater MP compared with Vios.

P/NEB was different among different brands with Inspiron Elite greater than Vios and greater than Pulmo-Aide $(P<.05)$. P/NEB remained stable for Pulmo-Aide and Inspiration Elite, but declined for Vios. The latter had a significant decline starting in wk 18.

MF/MP Slope. The brands behaved in a similar pattern at all times (see supplementary Table 1 and Fig. 1 in the material available at http://www.rcjournal.com). Pari Vios tended to have a greater absolute value of the MF/MP slope compared with Pulmo-Aide and Inspiration Elite. Pulmo-Aide tended to have a greater absolute value than Inspiration Elite. The difference in the slope when performing all pairwise comparisons was statistically significant with few exceptions. For wk 12, 18, and 24, statistical significance was not achieved, but the trend of Pari Vios having a greater slope than the other brands remained. In addition, Pari Vios had a greater variation around its trend compared with Pulmo-Aide and Inspiration Elite. This was especially true for wk 6-24, in which the standard error of the slope for Pari Vios was always greater than for the other 2 brands.

The Vios unit that stopped running at the end of wk 11 showed a significantly lower pressure at wk 6 while the flow was set at $2.5 \mathrm{~L} / \mathrm{min}$. The other unit that malfunc- tioned at wk 24 had lower pressures but these were not different from the other units.

\section{Particle Size Analysis}

All brands maintained baseline MMAD by wk 24 (see Table 3 in text and Table 2 in the supplementary material available at http://www.rcjournal.com). Pari Vios had larger MMAD than Pulmo-Aide and Inspiration Elite at all times, but it was only statistically significant at wk 0 for ViosPulmo-Aide $(P=.04)$ and at wk 24 for Vios-Inspiration Elite $(P=.004)$. Inspiration Elite had smaller MMAD than PulmoAide, with significance only at wk $12(P<.001)$.

Vios and Pulmo-Aide had a decrease in GSD at wk 24 compared with baseline $(P<.001)$. Inspiration Elite did not have significant change in GSD by wk 24 . Vios had significantly higher GSD than Pulmo-Aide at all times and higher GSD than Inspiration Elite at wk 0 and 12. Inspiration Elite had a larger GSD than Pulmo-Aide at wk 24.

$\mathrm{P} \%<5$ had no significant change with time for all brands. Inspiration Elite trended to have higher $\mathrm{P} \%<5$, followed by Pulmo-Aide and then Vios. The difference was significant compared with Vios at wk $24(P=.006)$ and with Pulmo-Aide at wk $12(P=.009)$.

\section{Breathing Simulation}

Vios and Inspiration Elite maintained baseline IM by the end of the study compared with baseline (see Table 3 in text and Table 2 in the supplementary material available at http:// www.rcjournal.com). Pulmo-Aide experienced significant increase in IM at wk $24(P<.001)$. There were differences among the brands. Inspiration Elite had the highest IM, with significance achieved in comparison to Pulmo-Aide at wk 0 and 12. Vios had higher IM than Pulmo-Aide at wk 0 and 12, but at wk 24 Pulmo-Aide was higher than Vios.

Pulmo-Aide had a significant increase in IM-RR at wk 12 and 24, but the others did not experience change. Inspiration Elite had the highest IM-RR among the brands, 


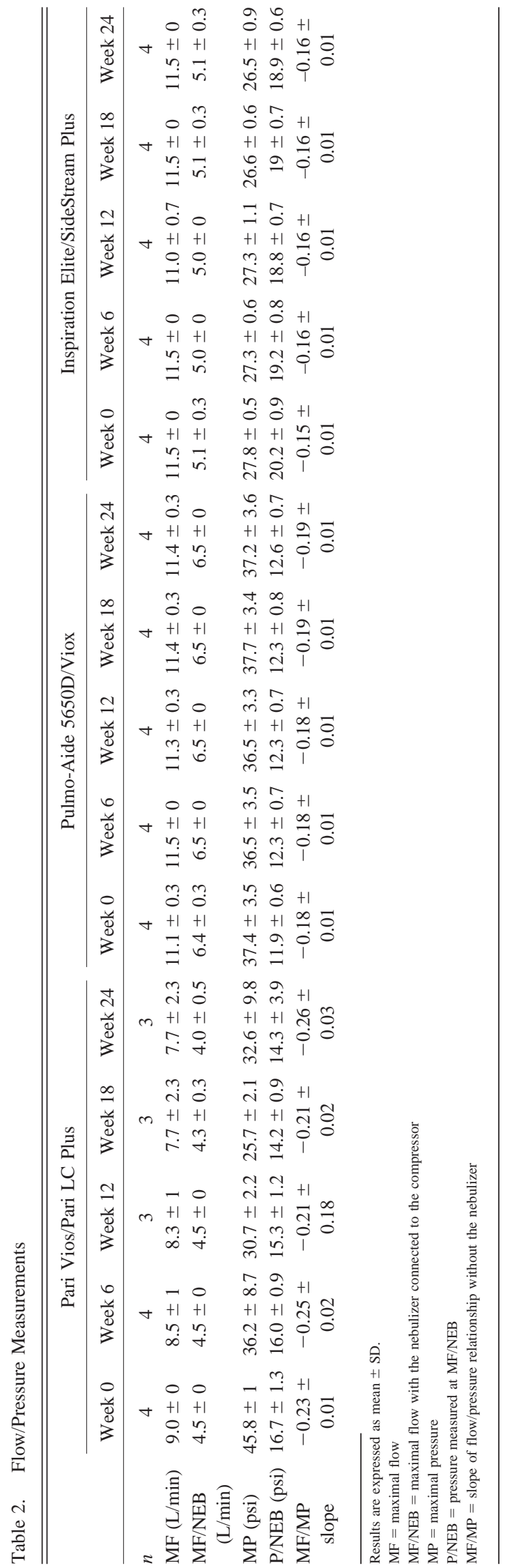

with significance at wk 0 and 12 when compared with Pulmo-Aide (2.9- and 2.4-fold difference, respectively). Vios had higher IM-RR than Pulmo-Aide that was significant at wk 0 and 12 (1.6-fold difference).

\section{Discussion}

This study provides flow/pressure and drug output characteristics of 3 compressor/nebulizer combinations commonly used by patients with CF and evaluates their performance over a 24-wk period of use typical of that population. It also shows differences in the performance among brands, which could provide data to practitioners to help them in the device selection process. These data should also provide manufacturers with additional information to help them improve their products.

Baseline flow and pressure values matched manufacturers' specifications, except for Pari Vios, which had higher MF and MP than specified. Comparison of baseline data with previously published compressor/nebulizer characteristics was not possible because none had used combinations similar to those used in our study ${ }^{16-20}$ In agreement with Smith et al, ${ }^{16}$ who studied other compressor/nebulizer combinations, we found that different compressor/nebulizer combinations have different flow/pressure relationships.

Pari Vios was the only compressor/nebulizer system that had significant declines in MF/NEB, MP, and P/NEB. Two units of Vios/Pari LC Plus stopped working by the end of the study. A decrease in MF and MF/NEB identified compressors that would soon fail. Practitioners need to be aware of this occurrence and have a contingency plan prepared so patients do not miss treatments for lack of a working compressor.

One could speculate that the 2 compressors that stopped working were faulty from the beginning. However, a careful review of the MP data shows that they all worked appropriately at wk 0 , as noted by a SD representing $1.4 \%$ of the mean. On wk 6 , the SD represented $24 \%$ of the mean, mainly due to the contribution of the unit that would stop working before wk 12. During wk 12 and 18, the SD represented $7-8 \%$ of the mean, showing that the second unit that malfunctioned in wk 24 was performing at the same level as the other ones. In addition, the progressive decline of the different units can be visualized (see Fig. 1 in the supplementary material available at http://www. rcjournal.com).

In contrast to Vios, flow and pressure characteristics remained stable for Pulmo-Aide and Inspiration Elite.

Maximal flows significantly varied across brands, but nebulizer design seemed to be more important than MF to determine IM-RR.

In agreement with Standaert et al, ${ }^{21}$ we found that all compressor/nebulizer combinations maintained baseline MMAD. Their study was limited to 100 runs, and ours was 


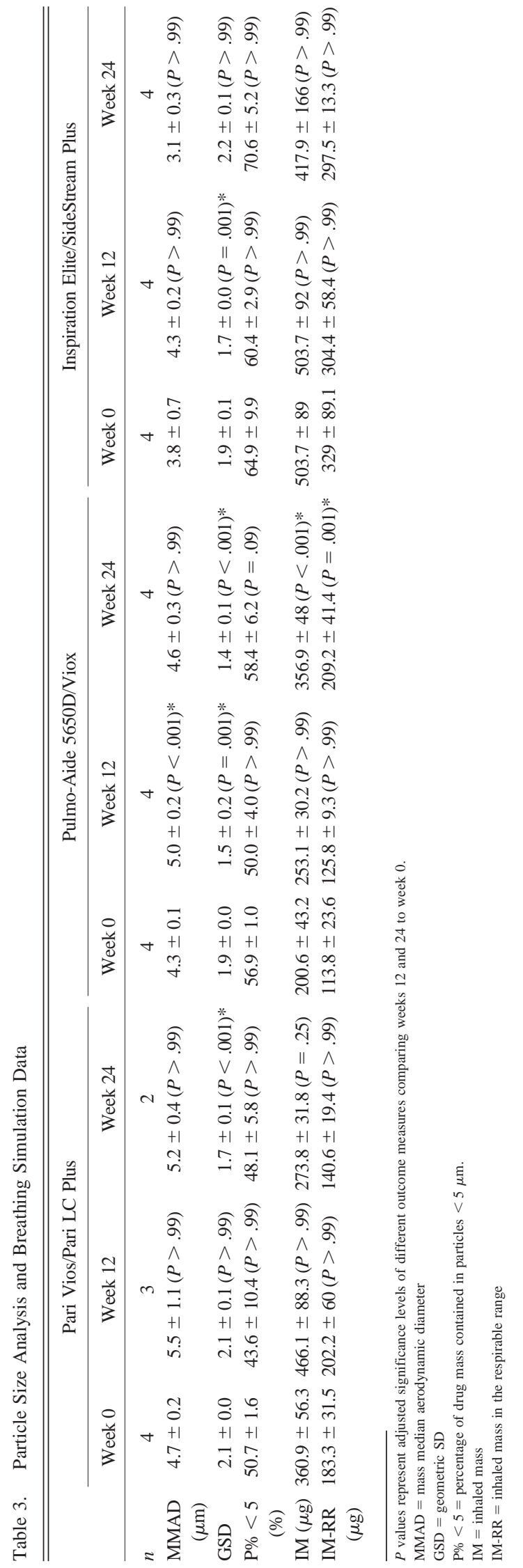

done after operating the equipment $1 \mathrm{~h}$ twice daily, $5 \mathrm{~d} / \mathrm{wk}$ for $24 \mathrm{wk}$, thus providing more long-term data. Inspiration Elite had the lowest MMAD compared with Pari Vios and Pulmo-Aide; however, these differences are not likely to affect intrapulmonary deposition. Aerosol remained polydisperse (GSD $\geq 1.22$ ) among all the brands, and the noted differences are not likely to be of clinical relevance.

Pari Vios and Inspiration Elite maintained IM-RR, whereas Pulmo-Aide experienced an unexplained increase by the end of the study period. Breath-enhanced nebulizers (Pari LC Plus and SideStream Plus) had higher IM-RR than the constant output nebulizers (Viox). Our results are in agreement with those of Bauer et al, ${ }^{14}$ obtained using arformoterol inhalation solution. We speculate that the stable IM-RR showed by the Pari Vios brand could be partially explained by the pressure fluctuations (MP) noted during the study. Another possible explanation is that the compressors will maintain a stable IM-RR while they remain operational. A third explanation for this finding could be the large individual variance at each time point.

Clinicians need to be aware of the differences in IM-RR that exist among different compressor/nebulizer combinations. Although a nearly 3 -fold difference may not be meaningful for albuterol, it could result in either underdosing or overdosing of other drugs, especially those with a narrow therapeutic index.

There are some limitations to the present study. Devices were operated for a total of $2 \mathrm{~h}$ daily without a solution, which could potentially minimize the effect of such use on the compressor/nebulizer systems and their characteristics. In addition, albuterol was the only medication used for particle size and breathing simulation measurements. If other solutions/suspensions had been used, characteristics could have potentially differed. Another limitation is that we tested only one breathing pattern (adult). However, although we expect the IM to be lower with a pediatric breathing pattern, we do not think that the choice of breathing pattern affects the validity of the findings. Longer studies with a larger number of units are needed to either verify or refute our findings. In addition, real life studies using the devices patients use daily are necessary to complement our findings.

\section{Implication of the Findings}

We found that not all compressor/nebulizer combinations can endure the use that occurs during CF care. In addition, significant differences among combinations in several outcome measures are present. Data would help healthcare providers to come up with recommendations of which compressor/nebulizer systems are better suited for actual use by patients with CF. Further longitudinal studies would have more relevant clinical implications than studying the characteristics of compressor/nebulizer units at the beginning of their use. Manufacturers need to consider 


\section{Longitudinal Evaluation of Compressor/Nebulizer Performance}

improving the ability of their compressors to withstand long-term use such as occurs in patients with $\mathrm{CF}$.

Because a decrease in MF is expected to increase treatment times, patients with $\mathrm{CF}$ should be asked at their clinic visits whether their treatments are taking longer. Periodic assessments of MF could also be easily implemented in clinical settings to screen for compressor units that are likely to fail.

\section{Conclusions}

The long-term use of compressor/nebulizer units under conditions similar to those of patients with $\mathrm{CF}$ affects their performance. Pari Vios was the most affected brand, experiencing significant changes in their flow/pressure characteristics, including 2 units that stopped working by the end of the study. Periodic assessment of MF could help identify compressors that will fail. IM and IM-RR remained stable throughout the study. Inspiration Elite was the brand most able to keep baseline flow/pressure characteristics and also had the smallest MMAD, highest $\mathrm{P} \%<5$, and IM-RR through the study.

\section{REFERENCES}

1. O'Sullivan BP, Freedman SD. Cystic fibrosis. Lancet 2009; 373(9678): 1891-1904.

2. Cystic Fibrosis Foundation Patient Registry. Annual data report to the Center Directors. Bethesda, MD: Cystic Fibrosis Foundation; 2010.

3. Ratjen FA. Cystic fibrosis: pathogenesis and future treatment strategies. Respir Care 2009;54(5):595-605.

4. Flume PA, O'Sullivan BP, Robinson KA, Goss CH, Mogayzel PJ Jr, Willey-Courand DB, et al. Cystic fibrosis pulmonary guidelines: chronic medications for maintenance of lung health. Am J Respir Crit Care Med 2007;176(10):957-969.

5. Mogayzel PJ Jr., Naureckas ET, Robinson KA, Mueller G, Hadjiliadis D, Hoag JB, et al. Cystic fibrosis pulmonary guidelines: chronic medications for maintenance of lung health. Am J Respir Crit Care Med 2013;187(7):680-689.

6. Tobi [package insert]. Novartis Pharmaceuticals Corporation, East Hanover, NJ; 2009.

7. Heijerman H, Westerman E, Conway S, Touw D, Döring G; consensus working group. Inhaled medication and inhalation devices for lung disease in patients with cystic fibrosis: a European consensus. J Cyst Fibros 2009;8(5):295-315.

8. Fuchs HJ, Borowitz DS, Christiansen DH, Morris EM, Nash ML, Ramsey BW, et al. Effect of aerosolized recombinant human DNase on exacerbations of respiratory symptoms and on pulmonary function in patients with cystic fibrosis. The Pulmozyme Study Group. N Engl J Med 1994;331(10):637-642.
9. Scherer T, Geller DE, Owyang L, Tservesta M, Keller M, Boden N, et al. A technical feasibility study of dornase alfa delivery with eFlow vibrating membrane nebulizers: aerosol characteristics and physicochemical stability. J Pharm Sci 2011;100(1):98-109.

10. Pulmozyme [package insert]. Genentech, South San Francisco, CA; 2010.

11. Donaldson SH, Bennett WD, Zeman KL, Knowles MR, Tarran R, Boucher RC. Mucus clearance and lung function in cystic fibrosis with hypertonic saline. N Engl J Med 2006;354(3):241-250.

12. Dolovich MB, Dhand R. Aerosol drug delivery: developments in device design and clinical use. Lancet 2011;377(9770):1032-1045.

13. Le Brun PP, de Boer AH, Heijerman HG, Frijlink HW. A review of the technical aspects of drug nebulization. Pharm World Sci 2000; 22(3):75-81.

14. Bauer A, McGlynn P, Bovet LL, Mims PL, Curry LA, Hanrahan JP. Output and aerosol properties of 5 nebulizer/compressor systems with arformoterol inhalation solution. Respir Care 2009;54(10):1342-1347.

15. Hess D, Fisher D, Williams P, Pooler S, Kacmarek RM. Medication nebulizer performance: effects of diluent volume, nebulizer flow, and nebulizer brand. Chest 1996;110(2):498-505.

16. Smith EC, Denyer J, Kendrick AH. Comparison of twenty three nebulizer/compressor combinations for domiciliary use. Eur Respir J 1995;89(3):157-159.

17. Standaert TA, Bohn SE, Aitken ML, Ramsey B. The equivalence of compressor pressure-flow relationships with respect to jet nebulizer aerosolization characteristics. J Aerosol Med 2001;14(1):31-42.

18. Standaert TA, Vandevanter D, Ramsey BW, Vasiljev M, Nardella P, Gmur D, et al. The choice of compressor effects the aerosol parameters and the delivery of tobramycin from a single model nebulizer. J Aerosol Med 2000;13(2):147-153.

19. Reisner C, Katial RK, Bartelson BB, Buchmeir A, Rosenwasser LJ, Nelson HS. Characterization of aerosol output from various nebulizer/compressor combinations. Ann Allergy Asthma Immunol 2001; 86(5):566-574.

20. de Boer AH, Hagedoorn P, Frijlink HW. The choice of a compressor for the aerosolisation of tobramycin (TOBI) with the PARI LC PLUS reusable nebuliser. Int J Pharm 268(1-2):59-69, 2003.

21. Standaert TA, Morlin GL, Williams-Warren J, Joy P, Pepe MS, Weber A, Ramsey BW. Effects of repetitive use and cleaning techniques of disposable jet nebulizers on aerosol generation. Chest 1998; 114(2):577-586.

22. Berlinski A, Hayden JB. Optimization of a procedure used to measure aerosol characteristics of nebulized solutions using a cooled next generation impactor. J Aerosol Med Pulm Drug Deliv 2010; 23(6):397-404.

23. Bauer A, McGlynn P, Bovet LL, Mims PL, Curry LA, Hanrahan JP. The influence of breathing pattern during nebulization on the delivery of arformoterol using a breath simulator. Respir Care 2009; 54(11):1488-1492.

24. Chavez A, McCracken A, Berlinski A. Effect of face mask static dead volume, respiratory rate and tidal volume on inhaled albuterol delivery. Pediatr Pulmonol 2010;45(3):224-229.

25. Barry PW, O'Callaghan C. Drug output from nebulizers is dependent on the method of measurement. Eur Respir J 1998;12(2):463-466.

This article is approved for Continuing Respiratory Care Education credit. For information and to obtain your CRCE

(free to AARC members) visit www.rcjournal.com

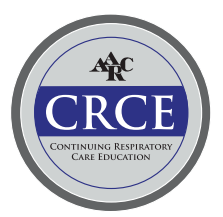

